\title{
Catanionic coacervate droplets as a surfactant-based membrane- free protocell model
}

\author{
Jean-Paul Douliez, ${ }^{*[a]}$ Nicolas Martin, ${ }^{[b]}$ Cédric Gaillard, ${ }^{[c]}$ Thomas Beneyton, ${ }^{[d]}$ Jean-Christophe Baret, ${ }^{[d]}$ \\ Stephen Mann, ${ }^{[b]}$ and Laure Beven, ${ }^{[a]}$
}

This is the author version of the manuscript published as

Catanionic Coacervate Droplets as a Surfactant-Based Membrane-Free Protocell Model, by JP Douliez et al. Angew. Chemie Int. Ed 2017

https://doi.org/10.1002/anie.201707139

\begin{abstract}
We report on the formation of surfactant complex catanionic coacervate droplets in mixtures of decanoic acid and cetyl pyridinium chloride or cetyl trimethyl ammonium bromide. We show that coacervation occurs over a broad range of composition, $\mathrm{pH}$ and ionic strength. The catanionic coacervates consist of elongated micelles, sequester a wide range of solutes including water-soluble organic dyes, polysaccharides, proteins, enzymes and DNA, and can be structurally stabilized by sodium alginate or gelatin-based hydrogelation. Taken together, the results suggest that catanionic coacervates could be exploited as a novel surfactant-based membrane-free protocell model.
\end{abstract}

Sequestration of biomolecules in compartments is a pre-requisite for the design and construction of bioreactors and minimal or artificial protocells..$^{[1-4]}$ Although lipid vesicles, vesosomes ${ }^{[5]}$ and polymersomes ${ }^{[6]}$ are commonly employed as cytomimetic models, ${ }^{[7]}$ their membrane impermeability restricts biomolecular uptake except in rare cases. ${ }^{[8,9]}$ Indirect procedures, such as the droplet transfer method ${ }^{[10]}$ are therefore required to produce high encapsulation efficiencies within vesicles. In contrast, membrane-free polymer and/or polyelectrolyte-based coacervates can spontaneously sequester biomolecules such as enzymes, DNA and RNA ${ }^{[3,11-13]}$ to

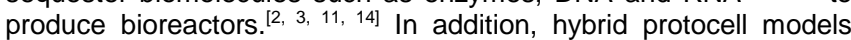
comprising coacervate droplets coated in lipid bilayers ${ }^{[13]}$ or vesicles ${ }^{[2]}$ have been developed in an attempt to control the passive exchange of sequestered molecules with the external medium. ${ }^{15}$ Coacervates have also been stabilized by particles affording Pickering-like water in water emulsion. ${ }^{[15]}$ Recently, a hybrid system based on fatty acid selfassembly has been reported, which undergoes a pH-dependent reversible transition between coacervate and vesicles. ${ }^{[9]}$ This feature

[a] Dr J-P Douliez and Dr L. Beven UMR 1332, biologie et pathologie du fruit, INRA, centre de Bordeaux, 33883 Villenave d'Ornon, France

E-mail: jean-paul.douliez@inra.fr

[b] Dr N. Martin and Prof. S. Mann Centre for Organized Matter Chemistry and Centre for Protolife Research, School of Chemistry, University of Bristol, Cantock's Close, BS8 1TS Bristol, UK

[c] Dr C. Gaillard UR BIA 1268, Biopolymères Interactions Assemblages, INRA, 44316 Nantes, France

[d] Dr T. Beneyton and Prof. J-C Baret CNRS, Univ. Bordeaux, CRPP, 115 Av. A. Schweitzer, 33600 Pessac, France is unique in surfactant-based systems, and has not been reported in polymer or polyelectrolyte systems. Coacervate-mediated formation of the vesicles was accompanied by a high encapsulation efficiency, except for negatively charged biomolecules such as DNA, which were not sequestered due to electrostatic repulsion with the anionic surfactant molecules. ${ }^{9}$ This suggested that the use of pure fatty acidbased coacervates as a potential protocell model would be limited in scope. In principle, it should be possible to use a mixed cationic/anionic system (catanionics ${ }^{[16]}$ ) to circumvent this limitation, but complex coacervation, i.e. clouding of catanionic systems, is uncommon for surfactants ${ }^{[17]}$, although it has been observed in few cases. ${ }^{[18,19]}$ Moreover, there are no known examples of the use of catanionic surfactant-based coacervates for the sequestration of functional biological molecules.

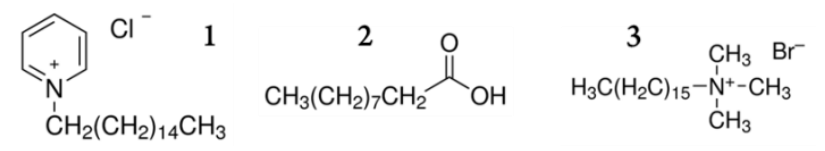

Scheme 1. Surfactants used to prepare complex catanionic coacervates: 1 cetyl pyridinium chloride (CPCl): 2, decanoic acid (DA); 3, cetyl trimethyl ammonium bromide, (CTAB).

Herein we report the assembly of complex catanionic coacervates across a broad $\mathrm{pH}$ range using a binary mixture of decanoic acid (DA) and a positively charged surfactant cetyl pyridinium chloride (CPCI) or cetyl trimethyl ammonium bromide (CTAB)) (Scheme 1). DA was chosen because it is commonly used in vesicle-based protocell models ${ }^{[4,20,21]}$ and is considered a plausible prebiotic constituent. ${ }^{[22}$ We demonstrate that proteins, enzymes and DNA are spontaneously sequestered within the catanionic coacervates, and show that the catanionic droplets, which consist of a matrix of elongated micelles, can be structurally stabilized by sodium alginate or gelatin-based hydrogelation.

Aqueous ( $\mathrm{pH} 4.5$ ) mixtures of CPCI/DA or CTAB/DA were prepared around the equimolar ratio. The mixtures were turbid and contained suspension of catanionic vesicles (Figure S1). Increasing the $\mathrm{pH}$ above 7 resulted in the onset of complex coacervation as evidenced by the formation of a polydisperse suspension of 5-50 $\mu \mathrm{m}$-sized spherical droplets after vigorous shaking (Figure 1A). The droplets were larger than observed in polymer-based coacervates probably because of differences in surface tension and viscosity (see below). Upon resting, droplets slowly coalesced into a bulk phase-separated 
upper layer over $2 \mathrm{~h}$ at $25^{\circ} \mathrm{C}$. The coacervate phase was transparent and non-birefringent, suggesting the formation of an isotropic phase. It was also viscous, which was consistent with the formation of a matrix of elongated micelles. ${ }^{[23]}$ The catanionic droplets were observed over a range of DA concentrations as depicted in partial phase diagrams prepared at a given CPCl $(27.9 \mathrm{mM})$ or CTAB (27.4 $\mathrm{mM}$ ) concentration (Figures $1 \mathrm{~B}$ and S2). The coacervate suspensions could be diluted up to ten times $([\mathrm{CPCl}]=1 \mathrm{mg} / \mathrm{mL})$ without destabilization of the droplets. Zeta potential measurements indicated that both positive and negative charged catanionic droplets were produced depending on the molar ratio between $\mathrm{CPCl}$ and DA, for different amounts of $\mathrm{NaOH}$ (Table S1). Upon decreasing the $\mathrm{pH}$, coacervates reformed vesicles showing that the transition was reversible (figure S1). To produce monodisperse populations of the catanionic CPCI/DA coacervate droplets, we adapted the above preparation procedure by using a microfluidic device to produce coacervate droplets of uniform size within suspended oil droplets (Figures 1C, S3 and S4).

The catanionic coacervates were stable in the presence of $\mathrm{NaC}$ and $\mathrm{MgCl}_{2}$ concentrations of up to $500 \mathrm{mM}$ and $100 \mathrm{mM}$, respectively. This feature is of importance for protocell models involving enzymatic reactions that require the presence of salt or divalent cations. However, coacervates became destabilized to produce a crystalline fatty acid salt on addition of $1 \mathrm{mM} \mathrm{CaCl} 2$ (Figure S5). As these solutes are known to cause disassembly of fatty acid vesicles, ${ }^{[4]}$ but can be ameliorated by various co-factors such as nucleobases ${ }^{[24]}$ and citric acid, ${ }^{[25]}$ we attributed the enhanced stability of the catanionic coacervate to strong electrostatic interactions between the oppositely charged surfactants.

Given the catanionic nature of the complex coacervate, we expected that a wide range of both positively and negatively charged molecular and macromolecular solutes would preferentially partition into the $\mathrm{CPCI} / \mathrm{DA}$ or $\mathrm{CTAB} / \mathrm{DA}$ droplets. Indeed, positively charged organic dyes such as acriflavin and negatively charged fluorescein were sequestered within the coacervate phase with partition coefficients greater than 200 (Figures 2A,B and S6), which was in marked contrast to similar studies using pure fatty acid coacervates that showed no uptake of negatively charged dyes. ${ }^{[23]}$ Interestingly, negatively charged FITC-dextran $(\mathrm{Mw}=500 \mathrm{kDa})$ was sequestered within the $\mathrm{CPCl} / \mathrm{DA}$ droplets provided that the coacervate was prepared with an excess of $\mathrm{CPCl}$ (Figures 2C,D), suggesting that in this case electrostatic interactions dominated the uptake behaviour. In general, it was difficult to determine the mechanisms responsible for sequestration of the various solutes due to the complexity of the multi-component systems investigated.

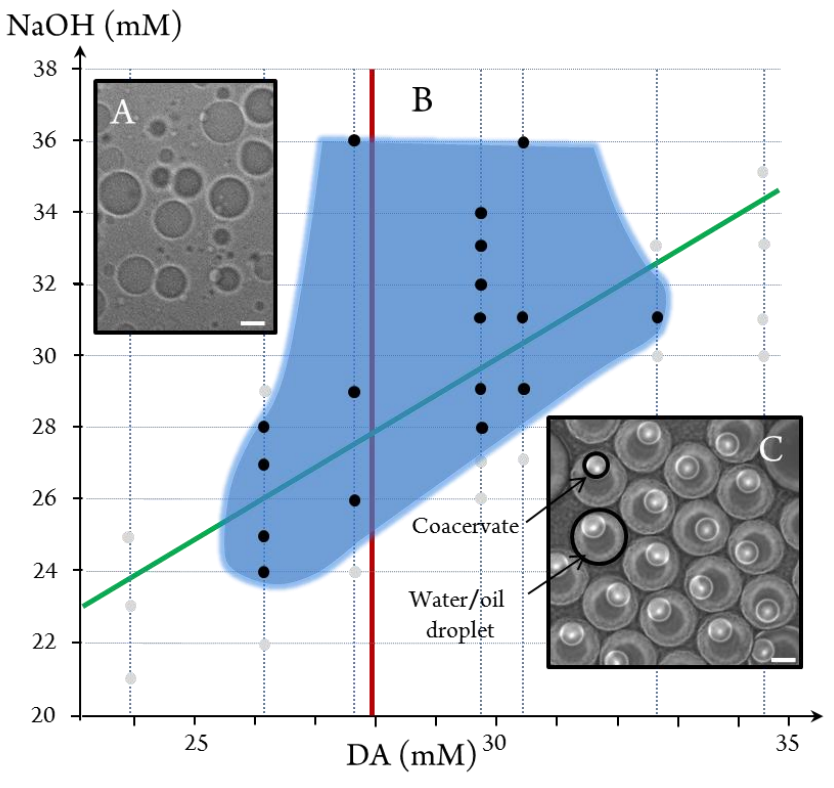

Figure 1. Catanionic coacervation in aqueous $\mathrm{CPCl} / \mathrm{DA} / \mathrm{NaOH}$ mixtures. (A) Spherical coacervate droplets as observed by bright field microscopy: sample composition; $\mathrm{CPCl}(27.9 \mathrm{mM}), \mathrm{DA}(28.5 \mathrm{mM}), \mathrm{NaOH}$ (30 mM); scale bar, $30 \mu \mathrm{m}$. (B) Partial phase diagram for the system CPCl $(27.9 \mathrm{mM}) / \mathrm{DA} / \mathrm{NaOH}$. Black dots and blue area represent samples and region, respectively, associated with the formation of catanionic droplets. Red and green lines refer to equimolar compositions of $\mathrm{CPCl} / \mathrm{DA}$ and $\mathrm{DA} / \mathrm{NaOH}$, respectively. All samples were prepared by addition of $\mathrm{NaOH}$ to vesicle mixtures prepared by varying the $\mathrm{CPCl} / \mathrm{DA}$ molar ratio ( $\mathrm{x}$ axis); similar results were obtained when the cationic surfactant was added to variable volumes of a micellar solution of sodium decanoate prepared at $\mathrm{pH} 10.5{ }^{[20]}$ and the $\mathrm{pH}$ then readjusted to various values. (C) Bright field microscopy image of catanionic CPCI/DA coacervate droplets encapsulated within water in oil droplets prepared by microfluidics. Scale bar, $50 \mu \mathrm{m}$.

Green fluorescent protein (GFP) (Figure $3 \mathrm{~A}, \mathrm{~B}$ ) and FITC-labeled glucose oxidase (FITC-GOx) (Figure 3C,D) were preferentially sequestered into or excluded from the droplets for CPCI/DA coacervates depending on the molar ratios between both surfactants. Moreover, sequestration of enzymes such as FITC-GOx or alkaline phosphatase occurred with retention of biocatalytic activity (Figure S7). Uptake of SYBR green-labelled dsDNA (prepared from a commercial genetic polymer) was observed to be $\mathrm{pH}$-dependent. At $\mathrm{pH} 7$, a fluorescent shell of the polymer was observed associated with the surface of individual CPCI/DA droplets, along with a low level of sequestration within the droplet (Figure 3E). The dsDNA corona was permeable to dye molecules (Nile red) and GFP (Figure S8), and increased the stability of the coacervate droplets with respect to coalescence. Increasing the $\mathrm{pH}$ to 9.5 resulted in high levels of $d s D N A$ sequestration and partial aggregation within the interior of the $\mathrm{CPCl} / \mathrm{DA}$ droplets (Figures $3 \mathrm{~F}$ and S8). In contrast, short FITClabelled ssDNA oligonucleotides were homogeneously sequestered inside the CPCl/DA droplets (Figure 3G). We prepared two distinct coacervate droplets populations that contained either FITC ( 3 coupled) or Cy5 (5'-coupled) complementary ssDNA oligonucleotides to investigate whether the coacervate droplets could sustain DNA hybridization. Mixing of the droplet populations produced a Förster resonance energy transfer (FRET) response (Figure S9), indicating that coalescence between the droplets led to exchange of the polymers and double-stranded hybridization within the coacervate matrix.
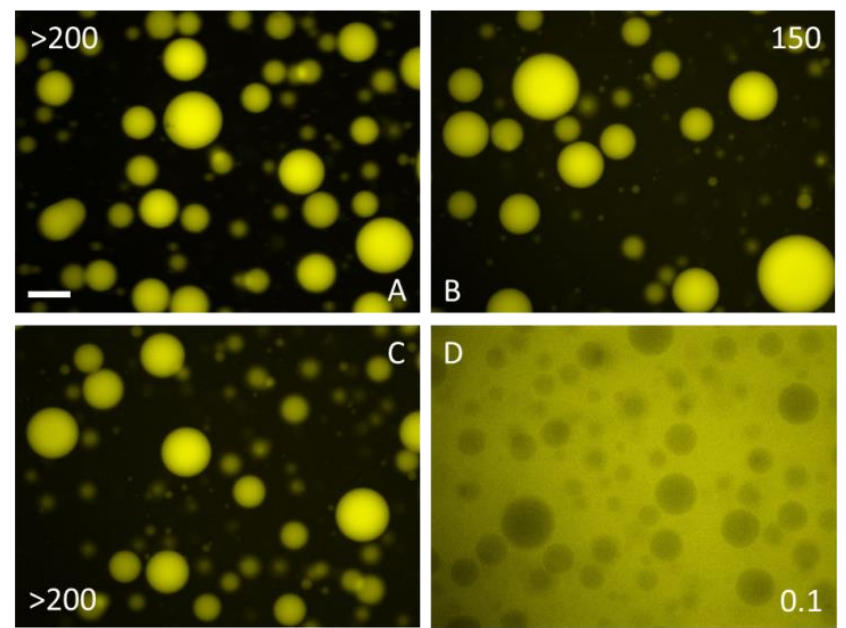

Figure 2. Dye and macromolecular sequestration in catanionic coacervates. $(\mathbf{A}, \mathbf{B})$ Epifluorescence images of coacervate droplets in the presence of $50 \mu \mathrm{M}$ fluorescein for two sample compositions; (A) $\mathrm{CPCl}$ (27.9 mM)/DA (26.1 $\mathrm{mM}) / \mathrm{NaOH}(25 \mathrm{mM})(\mathrm{CPCl}: \mathrm{DA}$ molar ratio $=1.07)$ and $(\mathbf{B}) \mathrm{CPCl}(27.9 \mathrm{mM}) / \mathrm{DA}$ $(29.7 \mathrm{mM}) / \mathrm{NaOH}(30 \mathrm{mM})(\mathrm{CPCl} / \mathrm{DA}=0.94)$. (C,D) $0.25 \mathrm{mg} / \mathrm{mL}$ FITC-dextran (MW: 500k) showing dependence of uptake on coacervate composition: (C) $\mathrm{CPCl}(27.9 \mathrm{mM}) / \mathrm{DA}(26.6 \mathrm{mM}) / \mathrm{NaOH}(27 \mathrm{mM})(\mathrm{CPCl}: \mathrm{DA}$ molar ratio = 1.05) showing preferential partitioning within the coacervate phase $(K>200)$; (D) $\mathrm{CPCl}(27.9 \mathrm{mM}) / \mathrm{DA}(30 \mathrm{mM}) / \mathrm{NaOH}(32 \mathrm{mM})(\mathrm{CPCl}: \mathrm{DA}$ molar ratio $=0.93)$ showing exclusion of FITC-dextran $(K=0.1)$; scale bar $=30 \mu \mathrm{m}$ for all images.

Finally, we inhibited coalescence of the catanionic coacervates to produce stabilized protocells by increasing the internal viscosity via 
incorporation of sodium alginate or gelatin-mediated in situ hydrogelation. No macroscopic phase separation was observed after 1 week when sodium alginate was mixed with a catanionic coacervate dispersion $(\mathrm{CPCl}: \mathrm{DA}=1.05$; alginate final concentration, $0.15 \mathrm{wt} \%)$. Optical microscopy images showed intact droplets with a mean size that was dependent on the alginate and $\mathrm{NaCl}$ concentration (Figure 4A-D), indicating that sequestration of alginate within the CPCI/DA droplets was effective in structurally stabilizing the coacervates. As addition of $\mathrm{Ca}^{2+}$ failed to cross-link the incarcerated alginate due to competing salt formation with DA, we used an alternative hydrogelation procedure involving the addition of gelatin (2 $\mathrm{wt} \%$ ) to a CPCI/DA (no alginate) coacervate dispersion held at $40^{\circ} \mathrm{C}$ for $1 \mathrm{~h}$, followed by cooling to room temperature. Depending on the rate of cooling and presence or absence of vortexing, dispersions of spherical and non-spherical hydrogelled droplets with variable mean size (Figures 4E,F) and retained protein-sequestration properties (Figure 4G) were produced. Changes in droplet size were attributed to an increase of viscosity favoring smaller droplets upon shearing. In all cases, hydrogelation resulted in a marked increase in the stability of the catanionic coacervates such that no coalescence was observed over a period of 1 week. This feature was reversible upon heating above $40^{\circ} \mathrm{C}$ since under these conditions the gelatin hydrogel was disassembled.
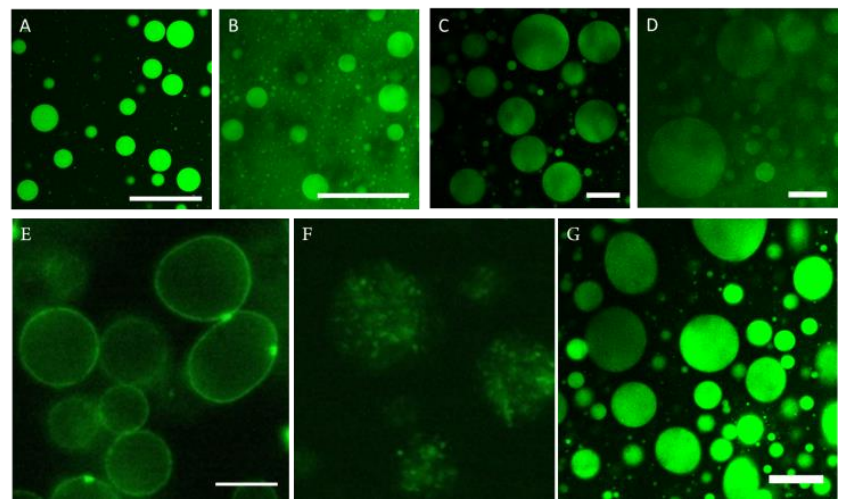

Figure 3. Macromolecular sequestration in catanionic coacervates. (A-D) Confocal fluorescence images of coacervate droplets in the presence of 0.1 $\mathrm{mg} / \mathrm{mL}$ GFP (A,B) and $0.25 \mathrm{mg} / \mathrm{mL}$ FITC GOx (C,D) for two sample compositions: (A,C) CPCl $(27.9 \mathrm{mM}) / \mathrm{DA}(27.6 \mathrm{mM}) / \mathrm{NaOH}(26 \mathrm{mM})(\mathrm{CPCl} / \mathrm{DA}$ = 1.01), and (B,D) CPCl $(27.9 \mathrm{mM}) / \mathrm{DA}(29.7 \mathrm{mM}) / \mathrm{NaOH}(31 \mathrm{mM})(\mathrm{CPCl} / \mathrm{DA}=$ 0.94). (E,F) Epifluorescence images of coacervate droplets in the presence of $0.25 \mathrm{mg} / \mathrm{mL}$ SYBR green-labelled dsDNA; (E) CPCl (27.9 mM)/DA (26.9 $\mathrm{mM}) / \mathrm{NaOH}(26 \mathrm{mM})(\mathrm{pH} 7, \mathrm{CPCl} / \mathrm{DA}=1.04)$ showing surface layer of adsorbed $d s \mathrm{DNA}$ on the coacervate droplets; (F) CPCl $(27.9 \mathrm{mM}) / \mathrm{DA}(26.9 \mathrm{mM}) / \mathrm{NaOH}$ $(28 \mathrm{mM})(\mathrm{pH} 9.5, \mathrm{CPCl} / \mathrm{DA}$ molar ratio $=1.04)$ showing preferential uptake and aggregation within the droplets. (G) Confocal image of coacervate droplets $(\mathrm{CPCl}(27.9 \mathrm{mM}) / \mathrm{DA}(29.8 \mathrm{mM}) / \mathrm{NaOH}(31 \mathrm{mM})(\mathrm{pH}=9.5 ; \mathrm{CPCl} / \mathrm{DA}=0.94)$ the presence of $1 \mu \mathrm{mol} / \mathrm{L}$ FITC-ssDNA showing homogeneous sequestration within the coacervate droplets.

In conclusion, we have described a surfactant catanionic system with the ability to self-organize into vesicles or coacervates over a broad range of $\mathrm{pH}$ and compositions as a step towards a novel surfactant-based membrane-free synthetic protocell model. The surfactant complex coacervates consist of a viscous matrix of elongated micelles, and can be viewed as multi-compartmentalized structures in which hydrophilic molecules are sequestered into the matrix and hydrophobic solutes into the core of the elongated micelles. The catanionic nature of the coacervate droplets facilitates the uptake and exchange of biomolecules such as polysaccharides, enzymes and DNA. Moreover, the droplets can be immobilized and released by reversible hydrogelation. Significantly, because the droplets also self-assemble into catanionic vesicles, they afford a hybrid system that can be switched between two different protocell types by varying the $\mathrm{pH}$. Transitions from the coacervates to vesicles should facilitate high levels of protein encapsulation into the vesicles yielding efficient bioreactors. ${ }^{[9]}$ Similarly, it should be possible to increase the transfer and encapsulation of genetic polymers (DNA RNA) and nucleotides into the catanionic vesicles via coacervate pre- loading. Interestingly, a catanionic vesicle-based protocell model has been proposed recently, ${ }^{[26]}$ and although $\mathrm{CPCl}$ and $\mathrm{CTAB}$ are not prebiotically relevant, decanoic acid has been considered as a plausible component on the early Earth, ${ }^{[2]}$ suggesting that coacervate-based protocell models involving catanionic surfactant mixtures could have relevance to origin of life studies. Finally, we propose that formation of DNA capsules and gelled coacervates using the above procedures could find multiple applications in materials chemistry.
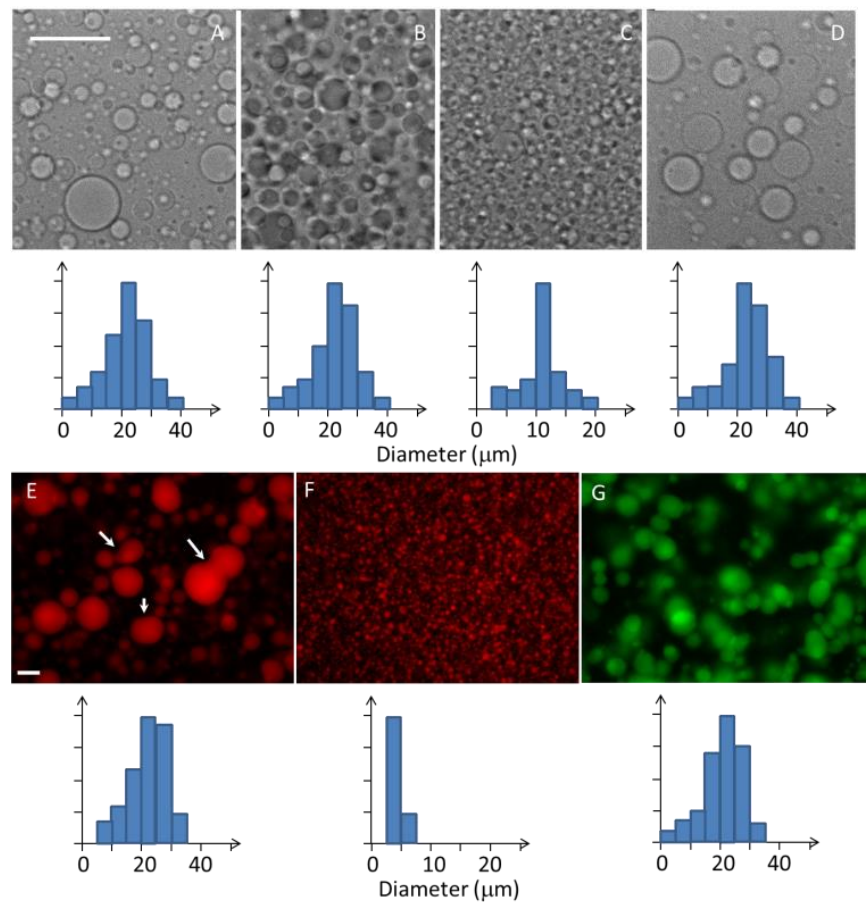

Figure 4. Structural stabilization of catanionic coacervate. (A-D) Bright field microcopy images (scale bar, $50 \mu \mathrm{m}$ ) of coacervate droplets (CPCl $(27.9$ $\mathrm{mM}) / \mathrm{DA}(26.6 \mathrm{mM}) / \mathrm{NaOH}(27 \mathrm{mM}) ; \mathrm{CPCl} / \mathrm{DA}=1.05)$ prepared in the presence of 0.15 wt $\%$ sodium alginate before $(\mathbf{A})$ and after creaming $(\mathbf{B})$, or in the presence of $0.3 \%$ sodium alginate together with (C) or without (D) $200 \mathrm{mM} \mathrm{NaCl}$. The lower panels show the corresponding changes in the droplet size distributions $(\mu \mathrm{m})$. (E-G) Epifluorescence images (scale bar, $20 \mu \mathrm{m}$ ) of hydrogelled catanionic coacervates (CPCl $(27.9 \mathrm{mM}) / \mathrm{DA}(26.9 \mathrm{mM}) / \mathrm{NaOH}(28$ $\mathrm{mM}$ ); $\mathrm{CPCl} / \mathrm{DA}=1.04$ ) obtained by heating samples in the presence of gelatin ( 2 wt\%) followed by rapid cooling over a period of $1 \mathrm{~h}$ with no vortexing (arrows highlight non-spherical droplets) (E); slow cooling and vigorous vortexing (F); and as in $\mathbf{E}$ but in the presence of $0.25 \mathrm{mg} / \mathrm{mL}$ GFP $(\mathbf{G})$. Red and green fluorescence observed in $\mathbf{E}$ and $\mathbf{F}$, or $\mathbf{G}$, respectively, originate from Nile red or GFP. The lower panels show the corresponding droplet size distributions $(\mu \mathrm{m})$.

\section{Experimental Section}

Experimental Details, additional figures and tables can be found in Supporting information

Acknowledgements: JPD would like to thank Eric Testet and Pierre Nassoy for the gift of the sodium alginate. TB and JCB would like to thank MaxSynBio for financial support. The epifluorescence microscopy was done in the Bordeaux Imaging Center, a service unit of the CNRS-INSERM and Bordeaux University, member of the national infrastructure France Biolmaging. NM and SM acknowledge the Wolfson Bioimaging Facility for access to confocal fluorescence microscopy. 
Keywords: Coacervates • Catanionics • Sequestration • microreactor $\cdot$ Protein Crowding

C. Fritiof, P. Luigi Luisi, The Systems View of Life, 2014; P. Luig Luisi, P. Stano, The minimal cell, 2011; P. L. Luisi, F. Ferri, P. Stano, Vol. 93, 2006, pp. 1-13; P. Stano, P. L. Luisi, Curr. Op. Biotech. 2013, 24, 633-638; J. W. Szostak, D. P. Bartel, P. L. Luisi, Nature 2001, 409, 387-390; D. Deamer, Chem. Soc. Rev. 2012, 41, 5375-5379; P.-A. Monnard, D. Deamer, Orig. life evol. biosph. 2001, 31, 147-155; D. Segré, D. Ben-Eli, D. W. Deamer, D Lancet, Orig. life evol. biosph. 2001, 31, 119-145; A. J. Dzieciol, S. Mann, Chem. Soc. Rev. 2012, 41, 79-85; S. Mann, Angew. Chem. Inter. Ed. 2013, 52, 155-162.

[2] D. C. Dewey, C. A. Strulson, D. N. Cacace, P. C. Bevilacqua, C. D. Keating, Nat. Commun 2014, 5.

[3] C. D. Keating, Acc. Chem. Res. 2012, 45, 2114-2124

K. Morigaki, P. Walde, Curr. Op. Coll. Inter. Sci. 2007, 12, 75-80.

[5] N.-N. Deng, M. Yelleswarapu, L. Zheng, W. T. S. Huck, J. Amer. Chem. Soc. 2016, 139, 587-590; E. T. Kisak, B. Coldren, C. A. Evans, C. B. a. J. A. Zasadzinski, Curr. Med. Chem. 2004, 11, 199-219.

[6] J. Huang, C. Bonduelle, J. Thévenot, S. Lecommandoux, A. Heise, J. Amer. Chem. Soc. 2012, 134, 119-122; S.-H. Kim, H. C. Shum, J. W. Kim, J.-C. Cho, D. A. Weitz, J. Amer. Chem. Soc. 2011, 133, 15165-15171; M. Marguet, L. Edembe, S. Lecommandoux, Angew. Chem. Inter. Ed.2012, 51, 1173-1176.

[7] E. Soussan, S. Cassel, M. Blanzat, I. Rico-Lattes, Angew. Chem. Inter. Ed. 2009, 48, 274-288.

[8] P. L. Luisi, P. Stano, T. de Souza, Orig. Life Evol. Biosph. 2014, 44, 313-317; P. Stano, E. D'Aguanno, J. Bolz, A. Fahr, P. L. Luisi, Angew. Chem. Inter. Ed. 2013, 52, 13397-13400.

[9] D. Garenne, L. Beven, L. Navailles, F. Nallet, E. J. Dufourc, J.-P Douliez, Angew. Chem. Inter. Ed. 2016, 55, 13475-13479.

[10] S. Pautot, B. J. Frisken, D. A. Weitz, Langmuir 2003, 19, 2870 2879; S. Pautot, B. J. Frisken, D. A. Weitz, Proc. Natl Acad. Sci. USA 2003, 100, 10718-10721; F. Caschera, V. Noireaux, Curr. Op. Chem. Biol. 2014, 22, 85-91; V. Noireaux, A. Libchaber, Proc. Natl Acad. Sci. USA 2004, 101, 17669-17674; V. Noireaux, Y. T. Maeda, A. Libchaber, Proc. Natl Acad. Sci. USA 2011, 108, 34733480 .

C. A. Strulson, R. C. Molden, C. D. Keating, P. C. Bevilacqua, Nat Chem. 2012, 4, 941-946.

A. I. Oparin, New York, 1953; T. Jia, C. Hentrich, J. Szostak, Orig. Life Evol. Biosph. 2014, 1-12; R. J. Ellis, Tr. Biochem. Sci. 2001 26, 597-604; A. P. Minton, Curr. Op. Str. Biol. 2000, 10, 34-39; J. M. Rohwer, P. W. Postma, B. N. Kholodenko, H. V. Westerhoff, 1998, 99, 10547-10552.

T. Y. Dora Tang, C. Rohaida Che Hak, A. J. Thompson, M. K. Kuimova, D. S. Williams, A. W. Perriman, S. Mann, Nat. Chem. 2014, 6, 527-533.

T. Y. Dora. Tang, D. van Swaay, A. deMello, J. L. Ross Anderson, S. Mann, Chem. Comm. 2015, 51, 11429-11432.

B. P. Binks, Langmuir 2017; B. T. Nguyen, W. Wang, B. R.

Saunders, L. Benyahia, T. Nicolai, Langmuir 2015, 31, 3605-3611. L. Chiappisi, H. Yalcinkaya, V. K. Gopalakrishnan, M. Gradzielski, T. Zemb, 2015, 293, 3131-3143; I. Rico-Lattes, M. Blanzat, S. Franceschi-Messant, E. Perez, A. Lattes, C. R. Chimie 2005, 8, 807-814.

[17] M. Wang, Y. Wang, Soft Matt. 2014, 10, 7909-7919; W. Zhao, Y Wang, Adv. Coll. Inter. Sci. 2017, 239, 199-212.

[18] S. I. Jenkins, C. M. Collins, M. G. Khaledi, Langmuir 2016; M. G Khaledi, S. I. Jenkins, S. Liang, Langmuir 2013, 29, 2458-2464.

[19] B. W. Barry, G. M. T. Gray, J. Coll. Inter. Sci. 1975, 52, 327-339; J Bhattacharjee, V. K. Aswal, P. A. Hassan, R. Pamu, J. Narayanan, J. Bellare, Soft Matt. 2012, 8, 10130-10140.

[20] C. L. Apel, D. W. Deamer, M. N. Mautner, Biochim. Biophys. Act 2002, 1559, 1-9.

[21] K. Morigaki, P. Walde, M. Misran, B. H. Robinson, Coll. Surf. A: 2003, 213, 37-44; D. W. Deamer, Nature 2008, 454, 37-38; P.-A Monnard, D. W. Deamer, Anat. Rec. 2002, 268, 196-207; P.-A Monnard, D. W. Deamer, D. Nejat, Meth. Enzym., Vol. 372, Academic Press, 2003, pp. 133-151; W. Hargreaves, D. W. Deamer, Biochem. 1978, 17, 3759-3768.

[22] G. Yuen, J. Lawless, E. Edelson, J. Mol. Evol. 1981, 17, 43-47; B. R. T. Simoneit, Adv. Sp. Res. 2004, 33, 88-94; A. I. Rushdi, B. R. T. Simoneit, Orig. Life Evol. Biosph. 2001, 31, 103-118.

[23] D. Garenne, L. Navailles, F. Nallet, A. Grélard, E. J. Dufourc, J.-P. Douliez, J. Coll. Interf. Sci. 2016, 468, 95-102.

[24] R. A. Black, M. C. Blosser, B. L. Stottrup, R. Tavakley, D. W Deamer, S. L. Keller, Proc. Natl Acad. Sci. 2013, 110, 1327213276.

[25] S. S. Mansy, J. P. Schrum, M. Krishnamurthy, S. Tobe, D. A Treco, J. W. Szostak, Nature 2008, 454, 122-125

[26] K. Kurihara, Y. Okura, M. Matsuo, T. Toyota, K. Suzuki, T. Sugawara, Nat. Comm. 2015, 6, 8352; K. Kurihara, M. Tamura, K.i. Shohda, T. Toyota, K. Suzuki, T. Sugawara, Nat. Chem. 2011, 3 , 775-781 
